\title{
Do capitalismo de plataforma à difusão dos aplicativos: apontamentos sobre novos nexos entre os circuitos da economia urbana em tempos de Covid-19
}

From platform capitalism to the diffusion of applications: notes on new connections between the circuits of the urban economy in Covid-19 times Del capitalismo de plataforma a la difusión de aplicaciones: notas sobre nuevas conexiones entre los circuitos de la economía urbana en tiempos de Covid-19 Du capitalisme de plateforme à la diffusion des applications : remarques sur les nouvelles liaisons des circuits de l'économie urbaine sous la Covid-19.

\section{Marina Regitz Montenegro}

\section{OpenEdition}

\section{Journals}

\section{Edição electrónica}

URL: http://journals.openedition.org/espacoeconomia/17256

DOI: 10.4000/espacoeconomia.17256

ISSN: 2317-7837

\section{Editora}

Núcleo de Pesquisa Espaço \& Economia

\section{Refêrencia eletrónica}

Marina Regitz Montenegro, « Do capitalismo de plataforma à difusão dos aplicativos: apontamentos sobre novos nexos entre os circuitos da economia urbana em tempos de Covid-19 », Espaço e Economia [Online], 19 | 2020, posto online no dia 03 setembro 2020, consultado o 10 dezembro 2020. URL : http://journals.openedition.org/espacoeconomia/17256 ; DOI : https://doi.org/10.4000/ espacoeconomia.17256

Este documento foi criado de forma automática no dia 10 dezembro 2020.

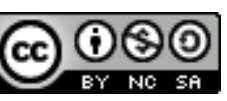

Espaço e Economia - Revista brasileira de geografia econômica est mise à disposition selon les termes de la licence Creative Commons Attribution - Pas d'Utilisation Commerciale - Partage dans les Mêmes Conditions 4.0 International. 


\section{Do capitalismo de plataforma à difusão dos aplicativos: apontamentos sobre novos nexos entre os circuitos da economia urbana em tempos de Covid-19}

From platform capitalism to the diffusion of applications: notes on new connections between the circuits of the urban economy in Covid-19 times Del capitalismo de plataforma a la difusión de aplicaciones: notas sobre nuevas conexiones entre los circuitos de la economía urbana en tiempos de Covid-19 Du capitalisme de plateforme à la diffusion des applications: remarques sur les nouvelles liaisons des circuits de l'économie urbaine sous la Covid-19.

\section{Marina Regitz Montenegro}

\section{Introdução}

1 No período atual, multiplicam-se os eventos portadores de uma racionalidade hegemônica fundada nos preceitos do neoliberalismo, redefinindo a inserção dos lugares em uma divisão territorial do trabalho renovada. Nesse período de globalização (SANTOS, 1996), as finanças, juntamente com a técnica e a informação, se reafirmam como variáveis determinantes conformando o motor da mais nova divisão do trabalho, tornada hoje definitivamente global. Segundo Silveira (2015, p.248), ao criar infinitos eventos subordinados, “(...) essas variáveis determinantes do período se tornam dominantes (...) e, portanto, produtoras de uma profusão de formas materiais e imateriais características da modernidade" (SILVEIRA, 2015, p.248).

2 Frente à aceleração contemporânea, a complexidade do mundo presente se revela, entre múltiplos aspectos, na dificuldade crescente de apreendermos o processo de 
totalização, o movimento totalizador, ou ainda, a geografização das variáveis-chave do período em cada formação socioespacial (SANTOS, 1978). Nesta direção, Harvey (2011) afirma que nossa tarefa reside na elaboração de uma interpretação teórica a respeito das relações espaciais e do desenvolvimento geográfico desigual sob o capitalismo, a qual deve abordar, entre outros, os processos diferenciais e as formas atuais assumidas pela urbanização. Caber-nos-ia, dessa forma, a construção de um olhar analítico atento às novas dinâmicas em nossas cidades, ou ainda, aos processos reveladores das desigualdades contemporâneas.

3 No momento atual, a pandemia global do Covid-19 se geografiza como evento de forma diferenciada nos lugares (SANTOS, 1996), cujas implicações sociais, econômicas e sanitárias profundas acentuam as desigualdades socioespaciais prévias, tornadas agora mais explícitas com sua chegada ao território brasileiro.

A imbricação trágica entre sistema de metabolismo antissocial do capital, crise estrutural e explosão do coronavírus (...) têm um claro caráter discriminatório em relação às classes sociais, pois é muito mais letal para a humanidade que depende de seu trabalho para sobreviver. A classe burguesa (...) tem seus fortes instrumentos de defesa (recursos hospitalares privilegiados, condições de habitação que lhes permite escolher as melhores condições de realizar suas quarentenas etc.), enquanto a classe-que-vive-do-trabalho luta para ver quem consegue sobreviver, isto é, sofrer a brutalidade da pandemia sem que se consubstancie a letalidade (ANTUNES, 2020, p. 12).

4 Nas cidades brasileiras, o contexto pandêmico de quarentenas prolongadas e restrição à circulação, iniciado no mês de março de 2020 tem, com efeito, revelado, de forma explícita, a contradição entre a possibilidade ou o privilégio do isolamento social por parte das camadas mais abastadas e a necessidade do trabalho fora de casa e, por conseguinte, da maior exposição ao risco de infecção por uma série de trabalhadores mais pobres, cujo sustento encontra-se nas ruas.

\section{A pobreza urbana e os primeiros impactos da pandemia}

5 No Brasil, as maiores cidades se caracterizam, certamente, como espaços de concentração das contradições socioespaciais no território nacional. Polarizam, por um lado, a modernização, a riqueza e a parcela política da produção, visto que apenas 15 metrópoles são responsáveis pela produção de 50,3\% do PIB nacional (IBGE, 2010). Contudo, concentram, ao mesmo passo, a pobreza e as estratégias de sobrevivência dos mais pobres, implicando, por conseguinte, não somente a fragmentação do território, mas a própria adaptação e segmentação da economia urbana (SANTOS, 1994). A pobreza e a indigência têm se tornado, com efeito, cada vez mais um fenômeno urbano e metropolitano no Brasil (ROCHA, 2006, 2009). Enquanto a participação dos indigentes e dos pobres rurais no total destes segmentos vem se reduzindo, a participação urbana $\mathrm{e}$ metropolitana cresceu significativamente no país nos últimos anos, haja vista, por exemplo, o aumento proporção de domicílios com rendimento médio mensal até $1 / 2$ salário mínimo per capita nos últimos 15 anos, a qual alcançou 18,5\%, do total de domicílios na Região Metropolitana de São Paulo e 25,2\% na RM do Rio de Janeiro em 2013 (IBGE/PNAD, 2013).

6 Nas grandes cidades, novos nexos e sinapses entre os circuitos da economia urbana emergem em um contexto em que se combinam, dialeticamente, o avanço da modernização, o adensamento urbano e o empobrecimento de parcela expressiva da 
população. Segundo Santos (1975), as divisões do trabalho coexistentes nas cidades podem ser compreendidas como circuitos da economia urbana que se distinguem em função dos diversos graus de tecnologia, capital e organização assumidos pelas atividades. Quando estes são altos, trata-se do circuito superior, incluindo sua porção marginal; quando são baixos, trata-se do circuito inferior, ou ainda, de toda uma economia da pobreza. O circuito inferior abarca, não obstante, não apenas suas atividades econômicas, mas a parcela da população nele involucrada pelo trabalho e pelo consumo. E embora todas as formas de trabalho encontrem-se integradas no espaço urbano, o poder de uso do território varia conforme a importância do agente considerado (SILVEIRA, 2011).

7 A análise das dinâmicas atuais dos circuitos da economia urbana nas cidades brasileiras implica a compreensão da conjuntura mais recente de transformações relativas à pobreza urbana no país. É importante pontuar, nessa direção, que durante os anos 2000, uma série de fatores contribuiu para a redução da pobreza e a expansão do consumo entre os pobres no país (NERI, 2011; POCHMANN, 2012). A capilarização de políticas públicas federais de transferência de renda pelo território, uma menor variação na estrutura de preços, o reajuste do valor do salário mínimo, o aumento da renda do trabalho, a crescente participação feminina no mercado de trabalho e a maior oferta de crédito, contribuíram, em conjunto, para a melhoria relativa das condições de vida da população pobre não só em áreas rurais, mas também nos espaços urbanos e metropolitanos.

8 Ao longo da última década, registraram-se, contudo, intensas transformações na conjuntura econômica e social brasileira. $\mathrm{O}$ desaquecimento do mercado de trabalho, o aumento do desemprego, a menor valorização do salário mínimo, a retração do consumo, a persistência do endividamento e a estagnação do processo de redução da pobreza e da miséria no país repercutiram, consequentemente, sobre as dinâmicas urbanas. Nessa direção, constata-se que apesar dos avanços alcançados ao longo dos anos 2000, o país voltou a registrar um forte aumento da população em situação de pobreza nos últimos anos. Entre 2016 e 2017, dois milhões de brasileiros se somaram aqueles em situação de pobreza, totalizando 54,8 milhões de pessoas, ou ainda, 26,5\% da população brasileira. Verificou-se, ademais, um aumento da extrema pobreza, visto que cerca de 1,7 milhão de brasileiros se somaram a esse contingente entre 2016 e 2018, alcançando 7,4\% da população do (IBGE, 2018).

9 Indicadores recentes referentes à renda média real domiciliar per capita revelam um agravamento do empobrecimento no país, visto que metade dos brasileiros sobreviviam com $\mathrm{R} \$ 438$ mensais em 2019. Dentro deste universo, os $10 \%$ mais pobres, equivalentes a 20,95 milhões de pessoas, sobreviviam com apenas R\$112 por mês (IBGE/PNAD, 2019). Observa-se, ademais, um aumento ininterrupto da desigualdade e da concentração de renda entre os brasileiros desde 2014. Segundo Neri (2019), os 50\% mais pobres da população brasileira tiveram um decréscimo de $17,1 \%$ de sua renda per capita do trabalho entre 2014 e 2019 , já os $1 \%$ mais ricos obtiveram um ganho de $10,11 \%$ em sua renda no mesmo período. Este quadro é agravado pelo crescimento do desemprego, que atingia, em 2019, mais de $12,7 \%$ da população economicamente ativa no país (IBGE, 2019).

10 A chegada da pandemia do novo coronavírus ao território brasileiro tem produzido, contudo, efeitos ainda mais devastadores sobre este grave quadro de crise social e econômica. Os impactos sobre a população e o mercado de trabalho já contabilizados 
apontam para um processo conjunto de aumento do desemprego, redução da renda, desestruturação de pequenas atividades e fechamento de empresas sem precedentes no país. Desde o início das medidas de restrição, em março de 2020, mais de 7,8 milhões de empregos foram eliminados, dos quais 5,8 milhões no chamado "setor informal". Registrou-se, ainda, o fechamento de 1,4 milhão de postos de trabalho "formais", dos quais 331,9 mil apenas no mês de maio deste ano (IBGE/PNAD-COVID19) ${ }^{1}$. Os trabalhadores não registrados que, por sua vez, integram em grande parte o circuito inferior da economia urbana ${ }^{2}$, têm sido especialmente penalizados pelas medidas de distanciamento social decorrentes do avanço da pandemia, visto que estes dependem, em grande medida, da circulação das massas e das economias de aglomeração.

11 Registrou-se, desde o início da pandemia, uma redução da ordem de 8,3\% da população ocupada, a qual engloba atualmente menos da metade daquelas em idade apta ao trabalho no país. Dados oficiais avaliam que 12,7 milhões de pessoas encontrem-se desempregadas e que 5,4 milhões estejam desalentadas, ou seja, tenham desistido de procurar emprego. Estima-se, porém, que o desemprego assuma, na realidade, dimensões muito maiores. Os efeitos econômicos da pandemia envolvem, destarte, uma forte retração da produção econômica. No mês de abril de 2020, primeiro mês completo de distanciamento social, foram registrados recuos da ordem de $11,7 \%$ do setor de serviços, $18,8 \%$ do setor industrial e $16,8 \%$ do comércio em relação ao mês anterior (IBGE/PNAD-COVID19).

12 A velocidade da redução na renda média do trabalhador revela o empobrecimento da população brasileira já decorrente dos efeitos da pandemia. Até março de 2020, o rendimento médio real do trabalho das pessoas ocupadas alcançava $R \$ 2320$; em maio desse ano, esse valor havia sido reduzido a $\mathrm{R} \$ 1899,00$. Em um universo de 19 milhões de pessoas afastadas do trabalho, 9,7 milhões ficaram sem remuneração em maio de 2020. O grau de carência da população brasileira expressa-se ainda no fato de que 58,6 milhões de pessoas, em 38,7\% dos domicílios brasileiros, receberam verbas do programa de Auxílio Emergencial do Governo Federal, sendo de $\mathrm{R} \$ 847$ o valor médio recebido por domicílio. Os mais pobres, sobretudo negros de menor escolaridade, têm sido a parcela da população mais afetada pela doença e pelos efeitos econômicos da pandemia (IBGE/ PNAD-COVID19). Para Antunes (2020), acercamo-nos, hoje, de uma profunda depressão que agravará ainda mais o processo de miserabilidade, aprofundando, consequentemente, as formas de precarização e subemprego no país.

Destarte, se em um momento anterior à pandemia, o território brasileiro se consolidava como uma arena de produções modernas, grande parte de sua população urbana seguia, porém, encontrando ocupação e renda através de atividades realizadas com recursos escassos, uma vez que o circuito superior tem se tornado cada vez menos empregador e o desemprego mais estrutural. Composta pelas mais diferentes formas de organização como microempresas pouco capitalizadas, prestadores de serviços banais, "trabalhadores autônomos", pequenos comércios, negócios domésticos e familiares, vendedores ambulantes etc - toda uma economia popular encontrava-se em expansão e dispersa pelos tecidos urbanos e metropolitanos (SILVEIRA, 2011; MONTENEGRO, 2014). Em um momento anterior à pandemia, os dinamismos dessa economia popular já se apresentavam, então, crescentemente complexos, uma vez que a expansão do consumo, a generalização do acesso e do uso produtivo da técnica moderna e a financeirização entre as camadas de baixa renda se combinavam ao empobrecimento estrutural. Esses processos tendem a adquirir, com a pandemia, contornos ainda imprecisos, visto que o 
circuito inferior tende a assumir, doravante, novas espessuras e expressões espaciais, capilarizando-se pelos tecidos urbanos. Ao agravamento da pobreza e do desemprego, soma-se, agora, a necessidade de maior exposição aos riscos à saúde e à letalidade por parte daqueles que dependem de seu trabalho nas ruas para sobreviver, aprofundando, assim, as desigualdades socioespaciais estruturais.

\section{Do capitalismo de plataforma à difusão dos aplicativos: novas dinâmicas dos circuitos da economia urbana}

14 Nessa direção, é preciso atentar às dinâmicas renovadas e de diferentes ordens que vêm transformado a realidade urbana nas grandes cidades brasileiras atualmente, redefinindo os nexos entre os circuitos da economia. Inserida nas totalidades do mundo e da formação socioespacial, a cidade conforma uma totalidade cuja explicação não se alcança em seus limites (SILVEIRA, 2011). Destarte, a busca pela compreensão das dinâmicas urbanas implica considerar as inter-relações entre as escalas da cidade, da região, do Estado territorial e da globalização, visto que as questões urbanas devem ser confrontadas também nos planos nacional, supranacional e global, ou seja, nas escalas onde a geografia do neoliberalismo é efetivamente definida (BRENNER, 2010). Com a modernização tecnológica e organizacional, amplia-se, hoje, o poder dos monopólios e oligopólios na definição da divisão territorial do trabalho contemporânea (SILVEIRA, 2019).

15 No período atual, a financeirização alia-se ao avanço da tecnificação em diferentes campos da vida social e econômica, permeando, inclusive, o âmbito da economia popular que passa a integrar novas atividades desenvolvidas a partir da banalização do desenvolvimento e do acesso aos aplicativos, dentre outros. Nesse processo, a digitalização da circulação vem assumindo um crescente protagonismo para a capitalização, aproximando-nos do denominado "capitalismo de plataforma". Enquanto intermediária socio-técnica do processo de capitalização, as plataformas digitais garantem não só a conectividade - por meio da conexão entre mercados -, mas o rastreamento permanente da informação e a realização da extração de renda no âmbito da própria circulação (LANGLEY e LEYSHON, 2016). Kostakis e Bauwens (2014) apontam, nessa direção, para a tensão característica dessa economia digital em que se tem, por um lado, a distribuição de uma infraestrutura, de uma base técnica, que garantiria supostamente a transformação de todos em pequenos empreendedores, e, por outro lado, a centralização da posse dessa infraestrutura nas mãos de oligopólios de plataformas privadas pertencentes a corporações globais financeirizadas.

Como as transformações recentes implicadas nesse capitalismo de plataforma têm impactado a economia popular nas grandes cidades brasileiras? Nos últimos anos, a viração popular (TELLES e HIRATA, 2007) nas cidades passou a incorporar novas atividades viabilizadas pelo uso de aplicativos em telefones celulares, dentre as quais se destacam aquelas de motoristas e de entregadores de serviços de aplicativos, entre outras. Grandes corporações internacionais como Uber, Cabify e 99, começaram a oferecer os serviços de transporte, corridas e entregas através de demandas por aplicativos no território brasileiro a partir do início dos anos 2010. Desde então, milhares de trabalhadores passaram a trabalhar como motoristas ou entregadores por meio de aplicativos. Estima-se, por exemplo, que atualmente mais de 600 mil pessoas estejam cadastradas como motoristas na Uber no país. Somam-se a estes, os 
entregadores de motos e bicicletas de aplicativos de entrega como Ifood, UberEats, Loggi e Rappi. Apenas na cidade São Paulo, havia, em 2019, cerca de 150 mil motoristas de Uber e 60 mil entregadores, totalizando $2,4 \%$ da força de trabalho da cidade (ORTELLADO, 2019).

17 No contexto presente de pandemia do novo coronavírus, trabalhadores entregadores de aplicativos não só ganharam maior visibilidade, como assumiram um papel vital de garantia do abastecimento cotidiano e do funcionamento da economia urbana, ao realizarem entregas de supermercados, restaurantes, farmácias etc. Conforme coloca Abílio $^{3}$, a forte presença dos entregadores nas ruas durante a quarentena explicita a contradição social entre aqueles que têm o privilégio ao isolamento e os que devem se arriscar e se sacrificar para sobreviver.

ercado de trabalho brasileiro, e mais propriamente, o circuito inferior da economia define-se como uma divisão social do trabalho com enorme variedade de atividades, mas também pela extrema adaptabilidade e flexibilidade dos atores. Motoristas e entregadores por meio de aplicativos têm passado, assim, a se somar recentemente às novas formas de trabalho desenvolvidas pela população de baixa renda na busca do sustento diário, seja como atividade exclusiva ou realizada de forma complementar a outras atividades. Dado o agravamento recente da conjuntura econômica e social do país, não apenas trabalhadores de baixa renda e pouca qualificação têm passado a atuar como motoristas e entregadores de aplicativos, mas também trabalhadores desempregados de formações variadas. Uma mobilidade social descendente - advinda do empobrecimento da chamada "nova classe média", do desemprego e do alto grau de endividamento ${ }^{4}$ entre a população de baixa renda - relaciona-se, assim, também às dinâmicas em questão.

Redefine-se, desta forma, o espectro de trabalho de uma parcela importante da população que passa a enfrentar renovadas formas de precarização. Graças à conectividade e mobilidade permanentes garantidas pelo advento dos smartphones, seus usuários passariam a integrar a dita economia do compartilhamento (MOROZOV, 2015), habilitando-se, por exemplo a novas formas de "empreendedorismo" e "parcerias" junto às empresas de aplicativos. A suposta liberdade de autogerenciamento do trabalhador autônomo (ABILIO, 2018) é acompanhada, contudo, pela generalização da supressão do vínculo empregatício, de direitos trabalhistas e de qualquer tipo de contrato mais estável entre as empresas e os trabalhadores. A expansão dessas atividades assenta-se, deste modo, na flexibilização normativa que autoriza novas modalidades de exploração e expropriação. A transferência de custos e riscos ao trabalhador completa a equação, revelando-nos aspectos da conformação de uma sociedade da terceirização total (ANTUNES, 2015). O controle das possibilidades técnicas e normativas pelas grandes empresas permite mobilizar e desmobilizar a força de trabalho constantemente, em um mercado supostamente autorregulado.

Milhares de trabalhadores têm passado, com efeito, a prestar serviços às empresas detentoras de aplicativos que, por sua vez, terceirizam o gerenciamento e a avaliação de seus "colaboradores", mas não deixam de deter a propriedade sobre eles, lucrando com a mesma (ABILIO, 2018). Embora este arranjo não seja novo, assume uma dimensão inédita com a chegada da Uber às grandes cidades brasileiras desde 2014. Segundo Ortelado (2019), se fosse considerada uma empregadora tradicional, a Uber teria mais funcionários que as 15 maiores empresas empregadoras somadas no Brasil. Empresas de aplicativos de transporte e entregas não se consideram, no entanto, empregadoras, mas 
fornecedoras da infraestrutura, medidadoras para a realização do trabalho. Conforme esclarece Abílio (2017), estaria em curso um processo de "uberização" do trabalho, em que as empresas, embora livres dos vínculos empregatícios, não deixam de definir os ganhos do trabalhador e reavaliar constantemente seu desempenho e produtividade.

“Trata-se então da consolidação da transformação do trabalhador em um nanoempreendedor de si próprio. E da empresa como uma simples provedora dos meios de trabalho (...) mediadora da relação entre oferta e procura. Estas mãos estão plenamente automatizadas nos softwares e algoritmos que são propriedade destas empresas. Ou seja, a intangibilidade deste controle e da relação de subordinação é desafiadora: a empresa é um aplicativo, o trabalhador é um parceiro, o gerenciamento é programado por um software, o gerente é uma multidão" (ABÍLIO, 2017, p.25).

21 Segundo Tozi (2018), a presença de economias de aglomeração, a periferização, o déficit de transporte público e os congestionamentos constantes explicariam a forte expansão do serviço de transporte por aplicativos nas metrópoles brasileiras. Cremos que a expansão do crédito, a intensificação do consumo, a aceleração da circulação e o aumento do comércio eletrônico estariam, por sua vez, entre os fatores envolvidos no crescimento do serviço de entregas solicitadas através de aplicativos. O serviço de entrega de alimentos por aplicativo, por exemplo, registrou um crescimento de $23 \%$ no país apenas entre 2017 e 2018. O Ifood, uma das empresas do ramo, atendeu, no país, cerca de 4,5 milhões de pedidos em julho de 2017, no mesmo mês do ano seguinte, já foram mais de 8,5 milhões, os quais alcançaram 20 milhões apenas em julho de 2019 (BRIGATTO, 2019). Números dessa ordem apontam para a dimensão das transformações em curso nas cidades brasileiras.

A chegada da pandemia do Covid-19 ao território brasileiro coincide, justamente, com a difusão das plataformas digitais e dos aplicativos pelo país. O contexto de isolamento residencial tem favorecido uma potencialização sem precedentes das demandas às empresas detentoras de plataformas digitais para entregas. Cabe destacar, nesse ponto, que os serviços de entrega foram classificados como atividades essenciais desde o primeiro momento da quarentena (art. $3^{\circ}$, XXII do Decreto n. 10.282/20). Em abril de 2020 , ocorreu a maior adesão a esses aplicativos, cuja instalação alcançou 22 milhões de aparelhos de celulares no país. A empresa Rappi, por exemplo, declarou um aumento de cerca de $30 \%$ das entregas em toda América Latina ${ }^{5}$.

Por outro lado, frente à explosão do desemprego e à queda de remuneração, milhares de trabalhadores têm buscado se cadastrar nas plataformas de aplicativos como entregadores durante a pandemia. Segundo relatório da empresa Rankmyapp ${ }^{6}$, nos meses de abril e maio, registrou-se, com efeito, um aumento de $200 \%$ na instalação de aplicativos para se trabalhar com delivery. À divisão entre os que têm direito ao isolamento e os que não têm, soma-se, assim, segundo $\mathrm{Abílio}^{7}$, aquela entre os que estão "uberizados" e os que querem se "uberizar".

O significativo aumento do número de pedidos de cadastros de trabalhadores junto às empresas de aplicativos para se tornar entregador durante a pandemia foi retratado em pesquisa coletiva realizada recentemente junto a 298 motoristas em 29 cidades brasileiras, dentre os quais, 9,4\% tornaram-se entregadores durante a pandemia (ABILIO et al., 2020). O estudo revela ainda, que, embora o número de entregas tenha crescido com a pandemia, remunerações e bonificações dos entregadores foram significativamente reduzidas ${ }^{8}$. Daí a hipótese de que as empresas detentoras do aplicativos estejam reduzindo a remuneração da força de trabalho do setor de forma 
orquestrada, sustentadas pelo aumento do contingente de trabalhadores de reserva tornados disponíveis com a pandemia.

Nesse movimento, assistimo, assim a emergência de novos termos da plataformização do trabalho. Se a pandemia tem significado, por um lado, a oportunidade de negócios para grupos corporativos oligopólicos, como as empresas de entregas por aplicativos, por outro, implica a aceleração, sem precedentes, do empobrecimento e da precarização da massa trabalhadora, redefinindo os contornos do circuito inferior da economia e suas relações de subordinação junto ao circuito superior. Isso ocorre entre aqueles que já estão "uberizados" e que, por sua vez, têm suas remunerações reduzidas, mas também entre os que estão tentando se "uberizar". Conforme coloca Braga ${ }^{9}$, o contexto da pandemia evidencia, ademais, a crescente desigualdade entre os trabalhadores de plataformas, haja vista a conformação de uma certa hierarquia, liderada por motoristas de carros individuais, seguida por motofretistas e entregadores em bicicletas. Neste universo, os entregadores representariam a base da categoria, cujas possibilidades de custear a própria atividade são relativamente inferiores e as condições de trabalho consideravelmente piores. Diante da ausência de qualquer tipo de renda, aumenta a disposição para a submissão a qualquer condição de trabalho.

Os serviços de transporte e entregas por aplicativo são controlados hoje por um grupo restrito de empresas do circuito superior da economia que conformam, por sua vez, verdadeiros oligopólios territoriais. A dependência do acesso ao aplicativo enquanto plataforma mediadora entre a oferta do serviço e a demanda é o que autoriza, por sua vez, a potencialização da exploração do trabalho e a expropriação de seus ganhos, haja vista a apropriação pelas empresas detentoras dos aplicativos de elevadas porcentagens ${ }^{10}$ de cada viagem ou entrega realizada pelo trabalhador. 0 trabalhador deve ainda assumir os demais custos envolvidos na realização das viagens, cujos preços encontram-se bastante depreciados, dificultando um rompimento da reprodução do ciclo da pobreza. Para Silveira (2019, p. 26):

"Os softwares que estão na base desses novos sistemas de trabalho têm como traços comuns o georreferenciamento, as bases de dados de trabalhadores e clientes, a tecnologia de comunicação, o rastreamento do trabalhador e o controle do tempo do serviço, o pagamento virtual e a avaliação do serviço. Desse modo, aumenta o grau de organização e alteram-se as condições gerais de emprego nos serviços banais. Há também uma tendência à unificação dos preços dos bens e serviços que passam a fazer parte de plataformas on line".

A oligopolização das plataformas dos serviços de entregas vem estabelecendo, ao mesmo passo, um novo crivo para os pequenos e médios negócios dos ramos de abastecimento e alimentação, os quais devem aderir aos aplicativos para ter acesso ao mercado consumidor. A mediação entre a oferta e a demanda garantida pelas plataformas alcança, no momento atual, um patamar inédito com as medidas de isolamento social desencadeadas pela pandemia. Nesse contexto, a adesão aos aplicativos de entregas passa a significar, paradoxalmente, a possibilidade de sobrevivência para pequenos negócios e, ao mesmo tempo, mais um canal de drenagem de seus recursos por parte do circuito superior, haja vista as altas porcentagens cobradas pelas empresas de aplicativos aos estabelecimentos pelo serviço de entrega ${ }^{11}$. Impõem-se, assim, novos elos de subordinação não só aos trabalhadores, mas aos pequenos negócios do circuito inferior e superior marginal.

28 Na busca da compreensão destes eventos que tomam as ruas das metrópoles brasileiras, consideramos que a explosão das atividades de motorista e entregador por meio de 
aplicativos pode ser investigada a partir da interrelação entre diferentes fatores que apontam, por sua vez, para novos nexos entre os circuitos da economia urbana no período atual. A expansão dos serviços em questão revela uma renovação de estratégias de empresas hegemônicas de um circuito superior global em que as tecnologias da informação assumem, além de um caráter de unicidade (SANTOS, 1996) um protagonismo crescente, abrigando, por sua vez, a possibilidade de driblar as diferentes leis e normas de cada formação socioespacial.

No capitalismo de plataforma, os usos oligopólicos do território, a normatização corporativa e a psicoesfera tornam-se mais complexos e de difícil apreensão. Em um contexto de pandemia, o malabarismo normativo das empresas para se desresponsabilizar pelos trabalhadores e transferir os riscos aos mesmos se potencializa ainda mais ${ }^{12}$. A conformação desse cenário nos convoca, assim, ao desvendamento de suas implicações sobre as dinâmicas urbanas e o cotidiano de parcela expressiva da população urbana que passa a ter suas vidas mediadas por novas formas de trabalho, potencializadas no contexto da pandemia.

\section{Do aprofundamento da subordinação à emergência da contra- racionalidades: paradoxos da técnica contemporânea}

O protagonismo dos aplicativos nos processos em curso aponta para o novo estágio da difusão da técnica da informação no período atual, assim como para as relações de complementaridade e subordinação entre os circuitos da economia urbana derivadas da unicidade técnica que caracteriza a época presente (SANTOS, 1996). A capilaridade alcançada por aparatos técnico informacionais como smartphones e notebooks enquanto objetos de consumo e instrumentos de trabalho estaria dando lugar, hoje, a uma nova fase de banalização técnica no cotidiano. Informatização, instantaneidade e produção de informação em escalas inéditas se combinam, permitindo novas formas de trabalho, mas também a emergência de novas formas de relações de dominação e subordinação entre os circuitos. A capilarização da internet pelos mais variados objetos técnicos do cotidiano aponta, ademais, para uma geografia do futuro que começa a se fazer presente, haja vista a generalização em curso da conectividade e da produção e "mineração" de dados, conformando, progressivamente, um cenário já denominado como "internet das coisas".

31 Não obstante, para além da banalização do acesso à telefonia celular e da universalização da internet, o advento dos aplicativos revela como tecnologias informacionais vêm sendo mobilizadas por grandes empresas como plataformas para a exploração do trabalho e para a expropriação da poupança popular. A técnica, compreendida aqui como a tecnologia e seus usos sociais, autoriza formas superlativas de precarização, mas também outros usos possíveis, como veremos a seguir.

32 A apreensão da realidade urbana atual passa, hoje, pela compreensão de processos multiescalares envolvidos na incorporação dos aplicativos no âmbito da economia popular. Fenômeno emblemático das transformações recentes na economia popular, a crescente banalização de técnicas modernas entre os agentes do menos capitalizados aponta para a dialética aí implicada, uma vez que sua incorporação aprofunda a dependência a uma técnica hegemônica por parte do circuito inferior (MONTENEGRO, 2014). A apropriação da tecnologia dos aplicativos pela economia popular tem autorizado, não obstante, a criação de novos protótipos, redefinindo seus usos possíveis 
e desafiando a hipertelia (SIMONDON, 1958) da técnica advinda do circuito superior. A criatividade e a flexibilidade dos agentes do circuito inferior se contrapõem, nessa direção, à rigidez técnica e organizacional dos algoritmos controlados por grandes empresas do ramo.

Dentre os aplicativos desenvolvidos na periferia de São Paulo, destaca-se, por exemplo, aquele criado por uma pequena empresa prestadora de serviços de motorista com organização simples, sem capitais importantes e sem tecnologias modernas. Enquanto modalidade alternativa de transporte, o "Ubra" configura um serviço que visa atender às demandas locais de deslocamento na favela de Brasilândia, na zona norte da cidade, haja vista a escassez do transporte público e a não cobertura da área pelas grandes empresas de aplicativos de transporte. Cabe destacar, nessa direção, que as empresas de aplicativos de transporte e entrega limitam suas áreas de atuação nas cidades brasileiras aos bairros centrais e aqueles com maior cobertura de transporte público. Criam, consequentemente, “'áreas de sombra' no território, ou seja, áreas a partir das quais, mesmo sendo tecnicamente possível, a operação do aplicativo torna-se inviável" (TOZI, 2017). Favelas e bairros mais periféricos sofrem, com efeito, restrições quanto ao perímetro de atendimento de empresas como Uber e 99, sob o argumento da segurança dos motoristas e usuários. Intensifica-se, por conseguinte, a periferização e a própria fragmentação do território.

34 O surgimento de novas atividades sustentadas em aplicativos no âmbito do circuito inferior não se restringe, certamente, aos serviços de transporte. Nas periferias, a concentração de uma população de baixa renda em áreas de alta densidade demográfica, a presença de um meio construído desvalorizado e intensamente ocupado, o aproveitamento das residências para a realização das mais diversas atividades, a proximidade do mercado e a densidade comunicacional conformam os conteúdos que garantem a reprodução e o surgimento constante de novas formas de trabalho do circuito inferior (MONTENEGRO, 2014). A expansão do crédito desburocratizado às camadas de baixa renda e a banalização do acesso a smartphones somam-se, hoje, a esses conteúdos, permitindo o desenvolvimento de novas atividades que passam a se organizar também através do advento de aplicativos de serviços diversos e de entregas não controlados por grandes empresas. Destacam-se, aí, os serviços de entrega de alimentos para consumo domiciliar, de beleza, de educação e até mesmo para denúncia de casos de violência.

A técnica volta-se, por meio desses usos, às necessidades concretas dos lugares, revelando-nos a importância da contiguidade e da solidariedade orgânica para o circuito inferior. A apropriação da tecnologia dos aplicativos por parte dos agentes do circuito inferior revela, assim, como o acesso combinado às técnicas antigas e mais modernas pode originar diferentes finalidades entre os atores não-hegemônicos; como estes objetos podem incorporar outros usos, conformando, assim, verdadeiras "técnicas doces" (GAUDIN, 1978), contrapondo-se ao enrijecimento tecnológico e normativo característico do período atual.

36 Nessa direção, a emergência de contra-racionalidades nascidas da apropriação de técnicas hegemônicas por parte de atores não-hegemônicos tem se dado, também, entre os entregadores de empresas de aplicativos no contexto da pandemia do Covid-19. Nos últimos meses, esses trabalhadores ampliaram suas formas de organização e associação, criando grupos, realizando debates, manifestações e até mesmo uma greve da categoria nas grandes cidades da América Latina. O movimento de 
organização e comunicação entre os trabalhadores se dá sobretudo em redes sociais que funcionam através de aplicativos como Whatsapp, Twitter e Instagram. Nesse ponto, cabe destacar a paralisação ocorrida em várias cidades brasileiras no dia 01 de julho de 2020, quando trabalhadores de aplicativos como Rappi, Loggi, Ifood, Uber Eats e James realizaram manifestações de grandes dimensões. Organizado por movimentos da categoria, além de grupos online de entregadores, o "Breque dos Apps", como foi chamado o movimento nas redes sociais, cobrou sobretudo melhoria das condições no trabalho, medidas e equipamentos de proteção individual contra o novo coronavírus ${ }^{13} \mathrm{e}$ aumento da remuneração.

37 Segundo Antunes (2020) com a pandemia, dissipa-se o desencantamento com a plataformização do trabalho e descontrói-se o mito do empreendedorismo. Em um cenário de enorme precarização da força de trabalho, aumenta o número de candidatos à contaminação e à letalidade que não podem fazer isolamento. Por outro lado, a apropriação popular das técnicas contemporâneas passa a abrigar, outrossim, a canalização das demandas desses trabalhadores e um possível embrião de sua organização política. Momentos de eclosão criativa revelam, destarte, como a difusão da técnica pode permitir a emergência de novos usos que escapam, em diferentes medidas, do controle previsto, assumindo, por conseguinte, certa autonomia (GAUDIN, 1978).

\section{Apontamentos finais}

38 Dada a intensidade das transformações recentes na economia urbana das metrópoles brasileiras, a grande cidade pode ser compreendida como um cenário crescentemente paradoxal (SILVEIRA, 2019). O empobrecimento, a diversificação dos usos da técnica contemporânea, a multiplicação dos consumos, a financeirização da pobreza e a renovação das formas assumidas pelo trabalho e pela precarização, com a ascensão do denominado "capitalismo de plataforma", são algumas das manifestações da complexidade da urbanização contemporânea.

39 A chegada da pandemia do Covid-19 potencializa esses processos já em curso, acentuando as contradições da sociedade e do território brasileiro. Urge, nessa direção, aprofundarmos, entre outros, nossa compreensão sobre como a banalização da tecnologia contemporânea, como as plataformas de aplicativos, têm implicado a conformação de novos nexos entre os circuitos da economia urbana nas cidades brasileiras, os quais envolvem, por um lado, a renovação das formas de exploração e sujeição do circuito inferior ao circuito superior, mas, também, uma apropriação criativa por parte da economia popular.

40 Para além da articulação horizontal interna a cada circuito da economia urbana, renovam-se, hoje, as articulações verticais entre os circuitos, aprofundando a subordinação do circuito inferior ao superior (SILVEIRA, 2015). Novos arranjos técnicos, organizacionais e normativos autorizam tais complementaridades hierárquicas, as quais têm assumido, por sua vez, expressões superlativas no contexto da pandemia. 


\section{BIBLIOGRAFIA}

ABÍLIO, Ludmila e MACHADO, Rosana. Uberização traz ao debate a relação entre precarização do trabalho e tecnologia. IHU On-line (UNISINOS), v.1, p. 20-28, 2017.

ABÍLIO, Ludmila Costhek; ALMEIDA, Paulo Freitas; AMORIM, Henrique; CARDOSO, Ana Claudia Moreira; FONSECA, Vanessa Patriota da; KALIL, Renan Bernardi; MACHADO, Sidnei. Condições de trabalho de entregadores via plataforma digital durante a Covid-19. Revista Jurídica Trabalho e Desenvolvimento Humano, Campinas, EDIÇÃO ESPECIAL - DOSSIÊ COVID-19, p. 1-21, 2020.

ANTUNES, Ricardo. A sociedade da terceirização total. Revista da ABET, v.14, n.1, p. 6-15, 2015.

ANTUNES, Ricardo. Coronavírus: O trabalho sob fogo cruzado. E-Book. São Paulo: Boitempo, 2020.

BRENNER, Neil. A globalização como reterritorialização: o reescalonamento da governança urbana na União Europeia. Cadernos Metrópole, 12, 24, p. 535-564, 2010.

BRIGATTO, Gustavo. Ifood chega a 21,5 milhões de pedidos por mês. <https://valor.globo.com/ empresas/noticia/2019/10/29/ifood-chega-a-215-milhes-de-pedidos-por-ms.ghtml>. Acessado em 29 de novembro de 2020.

FECOMERCIO SP. Pesquisa de Endividamento e Inadimplência das Famílias (PEIC). São Paulo 2019. <http://www.fecomercio.com.br/Estudos>. Acessado em 29 de novembro de 2019.

GAUDIN, Thyeri. L'écoute des silences, les institutions contre l'innovation?. Paris: Union Générale des Éditions, 1978.

HARVEY, David. O enigma do capital e as crises do capitalismo. São Paulo: Boitempo, 2011.

Instituto Brasileiro de Geografia e Estatística (IBGE). (2010). Censo Demográfico 2010. <http:// www.ibge.gov.br/home/estatistica/populacao/censo2010/default.shtm>. Acessado em 30 de março de 2020.

Instituto Brasileiro de Geografia e Estatística (IBGE). Pesquisa Nacional de Amostra por Domicílio 2003, 2007, 2009, 2011, 2013. <http://www.ibge.gov.br/home/estatistica/populacao/ trabalhoerendimento/pnad2013/default.shtm.> Acessado em 30 de março de 2020.

Instituto Brasileiro de Geografia e Estatística (IBGE). PNAD-COVID19. < https:// covid19.ibge.gov.br/pnad-covid/>. Acessado em 20 de junho de 2020.

KOSTAKIS, Vasilis e BAUWENS, Michel. Network Society and Future Scenarios for a Collaborative Economy. Basingstoke: Palgrave, 2014.

LANGLEY, Paul and LEYSHON, Andrew. Platform capitalism: the intermediation and capitalization of digital economic circulation. Finance and Society, p. 1-21, 2016.

MONTENEGRO, Marina. Globalização, trabalho e pobreza no Brasil nas metrópoles brasileiras. São Paulo: Annablume, 2014.

MOROZOV, Edward. Where Uber and Amazon rule: Welcome to the world of the platform. The Observer, 7 June, 2015.

ORTELLADO, Pablo. Está na hora de regular a Uber? Folha de São Paulo. <https:// www1.folha.uol.com.br/colunas/pablo-ortellado/2019/09/esta-na-hora-de-regular-auber.shtml?loggedpaywall>. Acessado em 17 de setembro de 2019. 
NERI, Marcelo. A Nova Classe Média. O lado brilhante da base da pirâmide. São Paulo: Editora Saraiva, 2011.

NERI, Marcelo. A escalada da desigualdade. Qual foi o impacto sobre a distribuição de renda e a pobreza? Rio de Janeiro: FGV Social, 2019.

POCHMANN, Marcio. Nova Classe Média? O Trabalho na base da pirâmide social brasileira. São Paulo: Boitempo, 2012.

ROCHA, Sonia. Pobreza e indigência no Brasil - algumas evidências empíricas com base na pnad 2004. Nova Economia, 16(2), p. 265-299, 2006.

ROCHA, Sonia. Série de dados e tabulações. Linhas de pobreza e de indigência. Rio de Janeiro: Instituto de Estudos do Trabalho e Sociedade, 2009.

SANTOS, Milton. L'espace partagé. Les deux circuits de l'économie urbaine des pays sousdéveloppés. Paris: M.-Th. Génin, Librairies Techniques, 1975.

SANTOS, Milton. O Espaço Dividido. Os dois circuitos da economia urbana dos países subdesenvolvidos. Rio de Janeiro: Francisco Alves, 1978.

SANTOS, Milton. A natureza do espaço: Técnica e tempo. Razão e emoção. São Paulo: Hucitec.

SANTOS, Milton. Por uma outra globalização. São Paulo/ Rio de Janeiro: Record, 2000.

SANTOS, Milton e SILVEIRA, María Laura. O Brasil: Território e sociedade no início do século XXI. Rio de Janeiro: Record, 2001.

SILVEIRA, María Laura. Economia política e ordem espacial: circuitos da economia urbana. In: SILVA, Cátia Antonia da (org.). Território e ação social: sentidos da apropriação urbana. Rio de Janeiro: Lamparina, p. 35-51, 2011.

SILVEIRA, María Laura. Modernização contemporânea e nova constituição dos circuitos da economia urbana. Geousp - Espaço e Tempo (Online), v. 19, n. 2, p. 246-262, 2015.

SILVEIRA, María Laura. Economia urbana hoje: categorias necessárias para sua compreensão. In: SANTOS, Erika.; RODRIGUES, Glauco; SANTOS Leandro; SILVA, Silvana.; RAMOS, Tatiana (orgs.). Território, Economia Urbana e Conflitos Territoriais. Rio de Janeiro: Letra Capital, v. 1, p. 17-35, 2019.

SIMONDON, Gilbert. Du mode d'éxistence des objets techniques. Paris: Aubier, 1958.

TELLES, Vera e HIRATA, Daniel. Cidade e práticas urbanas: nas fronteiras incertas entre o ilegal, o informal e o ilícito. Estudos Avançados 21 (61), p. 173-191, 2007.

TOZI, Fabio. Uso do território brasileiro por empresas globais de transporte por aplicativos: as estratégias de ação da Uber e as tensões advindas das resistências locais e regionais. In: XII ENANPEGE (Encontro Nacional da ANPEGE), 2017, Porto Alegre. Anais do XII ENANPEGE. Dourados: UFGD, p. 10270-10281, 2017.

TOZI, Fabio. As novas tecnologias da informação como suporte à ação territorial das empresas de transporte por aplicativo no Brasil. In: XV Coloquio Internacional de Geocrítica. Actas del XV Coloquio Internacional de Geocrítica Las ciencias sociales y la edificación de una sociedad post-capitalista.

Barcelona: Universitat de Barcelona, 2018. v. 1. 


\section{NOTAS}

1. A PNAD-COVID19é uma edição extraordinária da Pesquisa Nacional de Amostras por Domicílios realizada pelo Instituto Brasileiro de Geografia e Estatística para avaliar os efeitos do novo coronavírus sobre a população e o mercado de trabalho no país.

2. A informalidade é, nas estatísticas oficiais, associada à ausência de registro em carteira da mão-de-obra, ao status jurídico das atividades e ao não pagamento de impostos. Não há, portanto, equivalência direta entre os conceitos de setor informal e circuito inferior, definido como o universo de atividades urbanas caracterizadas por um baixo de grau de tecnologia, capital e organização.

3. ABÍLIO, Ludmila. Seminário on line "Trabalho e Uberização em tempos de pandemia: precariedade e gerenciamento dos trabalhadores just in time". Google Meet.14 de maio de 2020 . Acessado em 14 de maio de 2020.

4. Em 2019 , mais $63 \%$ das famílias brasileiras encontravam-se endividadas, entre as quais, $24 \%$ estavam inadimplentes (PEIC, 2019).

5. Pesquisa "Covid-19 e os impactos nos apps de delivery brasileiros", disponível em https:// pages.rankmyapp.com/impacto-apps-delivery-covid19/.

6. A empresa Rappi, teria registrado, um aumento do número de pedidos de cadastramento de entregadores em $300 \%$ no período (Idem).

7. ABÍLIO, Ludmila. Seminário on line "Trabalho e Uberização em tempos de pandemia: precariedade e gerenciamento dos trabalhadores just in time". Google Meet.14 de maio de 2020. Acessado em 14 de maio de 2020.

8. No período "antes da pandemia a remuneração era baixa, uma vez que $47,4 \%$ dos respondentes afirmaram que auferiam até $\mathrm{R} \$ 520,00$ por semana. Durante a pandemia, $71,9 \%$ declararam receber até $\mathrm{R} \$ 520,00$ e $83,7 \%$, até $\mathrm{R} \$ 650,00$. Ainda durante a pandemia, houve aumento de $100 \%$ dos que auferiam menos do que $\mathrm{R} \$ 260$ por semana" (ABILIO et al., 2020, p.12).

9. BRAGA, Ruy. Debate on line "Os impactos da crise do coronavírus na economia e no mundo do trabalho". Youtube. 30 de abril de 2020. Acessado em 30 de abril de 2020.

10. 0 custo da "mediação" entre trabalhador e consumidor a ser pago às empresas detentoras das plataformas alcança, em geral, 20 a $25 \%$ das tarefas realizadas.

11. No caso da empresa Ifood, as taxas cobradas aos restaurantes pelos serviços de entrega variam de 12 a $27 \%$, às quais ainda podem ser acrescidas mensalidades, conforme o plano de adesão do estabelecimento. "Ifoof dobra taxas de entrega". < https://tecnoblog.net/339719/ ifood-dobra-taxas-de-entrega-para-alguns-restaurantes >. Acesso em 04 de julho de 2020.

12. Durante a pandemia do Covid-19, uma série de decisões judiciais divergentes referentes aos trabalhadores de aplicativos têm se sucedido. Em maio de 2020, o Ministério Público acionou as empresas Rappi e Ifood em ação civil pública para a implementação de medidas de proteção aos trabalhadores sem questionar a natureza de seu vínculo empregatício. 0 Tribunal Regional do Trabalho da $2^{\mathrm{a}}$ Região emitiu, então, liminar favorável à implementação das medidas, a qual foi contestada por um mandado de segurança das empresas, isentando-as, assim, da responsabilidade sob a segurança e a saúde dos entregadores.

13. No contexto da pandemia, os trabalhadores entregadores vêm arcando com as medidas de proteção por conta própria na execução de seu trabalho, visto que as medidas adotadas pelas empresas têm se limitado à prestação de orientações (ABÍLIO et al., 2020). 


\section{RESUMOS}

No período atual, o avanço da tecnificação alia-se ao crescente protagonismo da digitalização da circulação, aproximando-nos do denominado "capitalismo de plataforma". No âmbito desse processo, novas dinâmicas têm transformado a realidade das grandes cidades, haja vista a centralidade alcançada pela capilarização dos aplicativos na redefinição de nexos entre os circuitos da economia urbana. Com a pandemia do Covid-19, certas modalidades de trabalho por plataformas de aplicativos ganham visibilidade, iluminando contradições estruturais da sociedade brasileira. A apreensão da realidade urbana passa, hoje, pela compreensão de processos multiescalares envolvidos na banalização dos aplicativos, os quais assumem expressões superlativas no contexto da pandemia.

In the current period, the advance of technification is allied to the growing role of digitization of circulation, approaching the so-called "platform capitalism". In the context of this process, new dynamics have transformed the reality of large cities, given the centrality achieved by the capillarization of applications in the redefinition of relationships between the circuits of the urban economy. With the Covid-19 pandemic, certain modalities of work by application platforms gain visibility, illuminating structural contradictions of Brazilian society. The apprehension of the urban reality today involves the understanding of multiscale processes involved in the trivialization of applications, which assume superlative expressions in the context of the pandemic.

En el período actual, el avance de la tecnificación se combina con el papel cada vez más importante de la digitalización de la circulación, acercándonos al llamado "capitalismo de plataforma". En este proceso, nuevas dinámicas han transformado la realidad de las grandes ciudades, dada la centralidad lograda por la capilarización de aplicaciones en la redefinición de enlaces entre los circuitos de la economía urbana. Con la pandemia de Covid-19, ciertos tipos de trabajo en plataformas de aplicaciones ganan visibilidad, iluminando contradicciones estructurales de la sociedad brasileña. La aprehensión de la realidad urbana actual implica comprender procesos multiescalares involucrados en 1 difusión de aplicaciones, que adquieren expresiones superlativas en el contexto de la pandemia.

A l'heure actuelle, l'avancement de la technification est à l'origine de la numérisation de la circulation. Dans ce qu'on appelle " capitalisme de plataforme ", des nouvelles dynamiques ont transformé la réalité des grandes villes, y compris l'importance des applications pour la redéfinition des rapports à l'intérieure des circuits de l'économie urbaine. Sous la Covid-19, certaines modalités de travail à travers des applications révèlent les contradictions structurelles de la société brésilienne en multiples échelles. 
ÍNDICE

Keywords: platform capitalism, technification, circuits of the urban economy, precariousness, pandemic.

Mots-clés: capitalisme de plateforme, technification, circuits de l'économie urbaine, précarisation, pandémie.

Palavras-chave: capitalismo de plataforma, tecnificação, circuitos da economia urbana, precarização, pandemia.

Palabras claves: capitalismo de plataforma, tecnificación, circuitos de la economía urbana, precariedad, pandemia.

\section{AUTOR}

\section{MARINA REGITZ MONTENEGRO}

Universidade de São Paulo (USP)

Pós-Doutora em Geografia. Departamento de Geografia. Pesquisadora Colaboradora montenegromarina@hotmail.com 